\title{
Circulating anti-mullerian hormone as predictor of ovarian response to clomiphene citrate in women with polycystic ovary syndrome
}

\author{
Wenyan $\mathrm{Xi}^{1}$, Yongkang Yang ${ }^{2}$, Hui Mao ${ }^{1 *}$, Xiuhua Zhao ${ }^{1}$, Ming Liu ${ }^{1}$ and Shengyu Fu ${ }^{1}$
}

\begin{abstract}
Background: To investigate the impact of high circulating $\mathrm{AMH}$ on the outcome of CC ovulation induction in women with PCOS.

Methods: This prospective cohort observational study included 81 anovulatory women with PCOS who underwent 213 cycles of CC ovarian stimulation. Serum AMH concentrations were measured on cycle day 3 before the commencement of CC in the first cycle, which were compared between responders and CC-resistant anovulation (CRA). Logistic regression analysis was applied to study the value of serum $\mathrm{AMH}$ for the prediction of ovarian responsiveness to CC stimulation. The receiver-operating characteristic (ROC) curve was used to evaluate the prognostic value of circulating $\mathrm{AMH}$.

Main outcome measures: Serum AMH levels.

Results: Women who ovulated after CC therapy had a significantly lower AMH compared with the CRA (5.34 \pm 1.97 vs.7.81 $\pm 3.49, P<0.001)$. There was a significant gradient increase of serum AMH levels with the increasing dose of CC required to achieve ovulation $(P<0.05)$. In multivariate logistic regression analysis, $\mathrm{AMH}$ was an independent predictor of ovulation induction by CC in PCOS patients. ROC curve analysis showed AMH to be a useful predictor of ovulation induction by CC in PCOS patients, having $92 \%$ specificity and $65 \%$ sensitivity when the threshold AMH concentration was $7.77 \mathrm{ng} / \mathrm{ml}$.
\end{abstract}

Conclusion: Serum AMH may be clinically useful to predict which PCOS women are more likely to respond to CC treatment and thus to direct the selection of protocols of ovulation induction.

Keywords: Anti-Müllerian hormone, Clomiphene citrate, Ovulation induction, Polycystic ovary syndrome

\section{Background}

Polycystic ovary syndrome (PCOS) is the most common endocrine disorder in women of reproductive age, with a prevalence of approximately $5-10 \%$. PCOS is the major cause of anovulatory infertility [1]. The recent studies suggest that anovulation results from ovarian follicle abnormalities in PCOS patitents are 2-fold [2, 3]. First, early follicular growth is excessive, thus women with

\footnotetext{
* Correspondence: xwyanzi@126.com

'Department of Obstetrics and Gynaecology, The Second Affiliated Hospital of Xi'an Jiaotong University, No. 157, Xiwu Road, Xi'an City 710004 Shaanxi Prov., China

Full list of author information is available at the end of the article
}

PCOS are characterized by an excessive number of small antral follicles (2- to 3-fold that of normal ovaries). Secondly, the selection of one follicle from the increased pool of selectable follicles and its further maturation to a dominant follicle does not occur. This second abnormality in the folliculogenesis is named the follicular arrest (FA) and explains the ovulatory disorder of PCOS. Although the FA has not received yet a clear and unanimous explanation, Anti-Müllerian hormone $(\mathrm{AMH})$ is considered as important contributors to this abnormality $[4,5]$.

AMH is producted specifically by granulose cells of early developing pre-antral and small antral follicles in 
the ovary. Serum AMH levels in women with PCOS are 2 - to 3-fold higher than in ovulatory women with normal ovaries [6, 7], which corresponds to the 2- to 3-fold increase in the number of small follicles seen in PCOS. The increased $\mathrm{AMH}$ has been hypothesized may reduce follicle sensitivity to FSH and oestradiol production, thus preventing follicle selection, resulting in follicle arrest at the small antral phase with the failure of dominance.

At present, the treatment of oligo- or anovulatory infertility is referred to as induction of ovulation. Clomiphene citrate (CC) is the treatment of first choice for ovulation induction in anovulatory women with PCOS. There are 20-25\% of women, however, remain anovulatory after receiving $\mathrm{CC}$ medication [8] and the exact cause of $\mathrm{CC}$ failure in some patients remain uncertain. Indentifying factors that determine the response of women with PCOS to $\mathrm{CC}$ will help selecting patients who are likely to benefit from this treatment, thus avoiding fruitless treatment and improving success rates.

Recently, AMH has been characterized as a promising novel clinical marker of ovarian reserve and predicting ovarian response to gonadotrophins during in vitro fertilization (IVF) in women without PCOS [9-11]. In PCOS women, we recent found AMH levels on day 3 of the IVF stimulation cycle still positively predict ovarian response to gonadotrophins [12]. However, different from our study, the predictive meaning of $\mathrm{AMH}$ was considered different between women with and without PCOS, for the authors found circulating AMH levels were negatively correlated with ovarian response to gonadotrophins during ovary induction in PCOS women [13]. Hence, the results of hitherto published studies are seemed not entirely in consensus. So we designed a study to investigate whether serum $\mathrm{AMH}$ has a role in predicting ovary response to $\mathrm{CC}$ treatment in a large cohort of infertile women with PCOS.

\section{Methods \\ Patients}

Subjects included 81 anovulatory women with PCOS who were referred to our department for ovulation induction between February 2012 and June 2014. The diagnosis of PCOS was based on the Rotterdam criteria, in which at least two of the following three criteria were met: oligomenorrhea or amenorrhea, hyperandrogenaemia, and sonographic appearance of polycystic ovaries [14]. Oligomenorrhoea was defined as cycles lasting longer than 35 days. Amenorrhea was defined as cycles lasting longer than 6 months. Hyperandrogenism was diagnosed either clinically (acne/hirsutism) and/or biochemically (testosterone $>0.7 \mathrm{ng} / \mathrm{ml}$ ). The ovary was considered polycystic on ultrasound scan if it contained $\geq 12$ follicles (2-9 $\mathrm{mm}$ in diameter) and/or measured $>10 \mathrm{ml}$ in volume. All patients presented with anovulatory cycles for at least 2 years. The inclusion criteria included: patients 35 years old or younger, BMI $\leq 30 \mathrm{~kg} / \mathrm{m}$ without previous ovulation induction and partners with normal semen parameters. No PCOS patient had evidence of hyperprolactinemia, Cushing's syndrome, congenital adrenal hyperplasia or androgen-secreting tumors.

\section{Ethical approval}

This study was approved by the Ethics Committee of The Second Affiliated Hospital of $\mathrm{Xi}$ an Jiaotong University. All participants provided their informed consent before their involvement in this study.

\section{Clomiphene citrate treatment}

All women received an initial dose of $50 \mathrm{mg} / \mathrm{d}$ CC from cycle d3 until d7 after spontaneous or progestageninduced withdrawal bleeding. In the case of an absent ovarian response, daily dosage was increased to $100 \mathrm{mg}$ in the following cycles. If ovulation occurred, the dose remained unaltered during subsequent cycles. First ovulation was used as the end point. The duration of all patients included in the study was at least three treatment cycles. Ovulation was assessed by midluteal serum progesterone measurement (levels $>10 \mathrm{ng} / \mathrm{ml}$ indicating ovulation) combined with transvaginal sonographic monitoring of follicle growth until the appearance of a preovulatory follicle (mean diameter $\geq 18 \mathrm{~mm}$ ) and subsequent follicle rupture. Responders were defined as patients who ovulated during $\mathrm{CC}$ therapy, independent of the dose administered. Failure to ovulate in three CC cycles despite stimulation with the maximum dose (100 mg/d) was referred to as CC-resistant anovulation (CRA). Clinical pregnancy was defined as the presence of a gestational sac with cardiacactivity as detected by transvaginal ultrasound after 35 days of ovulation.

\section{Hormone assays}

Blood samples were collected on cycle day 3 before the commencement of $\mathrm{CC}$ in the first cycle of treatment to measure baseline serum concentrations of AMH. AMH was measured by using a second-generation enzymelinked immunosorbent assay (ELISA) (Immunotech Beckman Coulter Laboratories, Villepinte, France). The analytical sensitivity of this assay is $0.14 \mathrm{ng} / \mathrm{mL}$. Intraand inter-assay coefficients of variation were $\leq 12.3$ and $\leq 14.2 \%$, respectively.

Serum other hormonal concentrations including luteinizing hormone (LH), follicle stimulating hormone $(\mathrm{FSH})$, testosterone $(\mathrm{T})$, insulin and progesterone were measured using electrochemiluminescence immunoassay (Roche Diagnostics GmbH, Mannheim, Germany). Insulin resistance, defined by the homeostasis model assessment insulin resistance index (HOMA-IR), was calculated using 
the following equation: HOMA-IR = fasting insulin (IU/ $\mathrm{ml}) \times$ fasting glucose $(\mathrm{mmol} / \mathrm{L}) / 22.5[15]$.

\section{Transvaginal scan}

In the same morning of the blood tests, a transvaginal ultrasound scan was performed to assess the ovarian volume (milliliters), and antral follicles count (AFC). The volume of each ovary was calculated by measuring the ovarian diameters (D) in three perpendicular directions and applying the formula for an ellipsoid: $\mathrm{D} 1 \times \mathrm{D} 2 \times$ D3 $\times 0.5236$. For the determination of the AFC, we calculated small follicles with a diameter between 2 and $9 \mathrm{~mm}$, following the recommendations as described previously [16].

\section{Statistical analysis}

The Statistical Package for Social Sciences (SPSS 17.0, Chicago) was used for statistical analysis. Differences between responders and nonresponders were tested using the $t$-test, nonparametric test (Mann-Whitney $\mathrm{U}$ ) and $\chi 2$-test as appropriate. Spearman's correlation coefficient was calculated to evaluate the relation of $\mathrm{AMH}$ to other characteristics of PCOS. Using the results of the ROC analysis, we defined an appropriate threshold level for $\mathrm{AMH}$ and determined the sensitivity and specificity of that threshold. Logistic regression analysis was applied to study the value of serum AMH and other study variables for the prediction of ovarian responsiveness to $C C$ stimulation. $P<0.05$ was considered statistically significant. Multiple logistic regression analysis with forward selection of parameters was applied with $P<0.10$ for entry.

\section{Results}

The study included 81 anovulatory women with PCOS who received 213 cycles of CC ovulation induction. Patient characteristics are shown in Table 1. Of the 81 women included in the study, 43 (53.1\%) ovulated during ovulation induction with CC $50 \mathrm{mg} / \mathrm{d}$. This number increased to $52(64.2 \%)$ after increasing CC dose up to the100 mg/d, 29(35.8\%) remaining anovulatory were considered CRA (Fig. 1). A total of 26(32.1\%) women conceived during up to three cycles of CC treatment. Of the 213 CC cycles, ovulation occurred in 114 cycles $(53.5 \%)$ and pregnancy in 26 cycles $(12.2 \%)$.

Women were divided into two groups based on their response to clomiphene citrate treatment: $C C$ responders $(n=52)$ and CRA $(n=29)$. Patients who ovulated had a significantly lower serum AMH concentration compared with nonresponders $(5.34 \pm 1.97$ vs.7.81 $\pm 3.49, P<0.001)$. AFC and ovarian volume from responders group were statistically significantly lower than from the CRA group $(P<0.05)$. There were no significant differences between the groups in mean age, BMI, FSH, LH, LH/FSH, T and HOMA-IR (Table 1). In addition, patients who conceived had a significantly lower serum AMH concentrations compared with that of those who did not conceive $(4.81 \pm 2.06$ vs. $6.89 \pm 2.95 \mathrm{ng} / \mathrm{ml}, P<0.01$ ) (Table 2). When CCresistant patients were excluded from analysis of pregnancy, serum AMH concentrations were comparable in women achieving pregnancy $(n=26)$ and those not conceiving $(n=26)(4.81 \pm 2.06 \mathrm{ng} / \mathrm{ml}$ vs $5.67 \pm 1.76 \mathrm{ng} / \mathrm{ml}, P>0.05)$.

Spearman's correlations between serum AMH concentrations and other characteristics of PCOS showed AMH significantly correlated with serum LH $(r=0.253, P<0.05)$, ovarian volume $(r=0.297, P<0.01)$ and AFC $(r=0.296$, $P<0.01)$. No statistically significant correlation between

Table 1 Baseline characteristics of 81 anovulatory women with PCOS who received CC ovulation induction, and separated for women who do (responders) or do not ovulate (CRA) after CC induction of ovulation

\begin{tabular}{|c|c|c|c|c|}
\hline \multirow[t]{2}{*}{ Variable } & All participants & CC responders & CRA & \multirow[t]{2}{*}{$P$ value } \\
\hline & $n=81$ & $n=52$ & $n=29$ & \\
\hline Age (years) & $26.62 \pm 2.53$ & $26.98 \pm 2.48$ & $25.97 \pm 2.53$ & NS \\
\hline BMI (kg/m2) & $23.79 \pm 2.78$ & $23.53 \pm 2.81$ & $24.24 \pm 2.71$ & NS \\
\hline $\mathrm{LH}(\mathrm{IU} / \mathrm{L})$ & $8.29 \pm 2.37$ & $8.01 \pm 2.29$ & $8.77 \pm 2.49$ & NS \\
\hline $\mathrm{FSH}(\mathrm{IU} / \mathrm{L})$ & $5.73 \pm 1.19$ & $5.79 \pm 1.28$ & $5.62 \pm 1.03$ & NS \\
\hline $\mathrm{LH} / \mathrm{FSH}$ & $1.52 \pm 0.59$ & $1.46 \pm 0.58$ & $1.63 \pm 0.62$ & NS \\
\hline $\mathrm{T}(\mathrm{ng} / \mathrm{ml})$ & $0.56 \pm 0.25$ & $0.55 \pm 0.23$ & $0.58 \pm 0.29$ & NS \\
\hline HOMA-IR & $3.18 \pm 1.92$ & $3.11 \pm 2.16$ & $3.31 \pm 1.41$ & NS \\
\hline Ovarian volume (ml) & $10.43 \pm 1.58$ & $9.7 \pm 1.32$ & $10.49 \pm 1.74$ & $<0.05$ \\
\hline $\operatorname{AFC}(n)$ & $16.11 \pm 3.71$ & $15.44 \pm 3.17$ & $17.31 \pm 4.33$ & $<0.05$ \\
\hline $\mathrm{AMH}$ & $6.22 \pm 2.8$ & $5.34 \pm 1.97$ & $7.81 \pm 3.49$ & $<0.001$ \\
\hline
\end{tabular}

Note: Values are mean \pm SD unless otherwise indicated

CRA CC-resistant anovulation, BMI body mass index, LH luteinizing hormone, FSH follicle stimulating hormone, $T$ testosterone, $H O M A-I R$ the homeostasis model assessment insulin resistance index, $A F C$ antral follicles count, $A M H$ antimüllerian hormone, NS Not statistially significant 


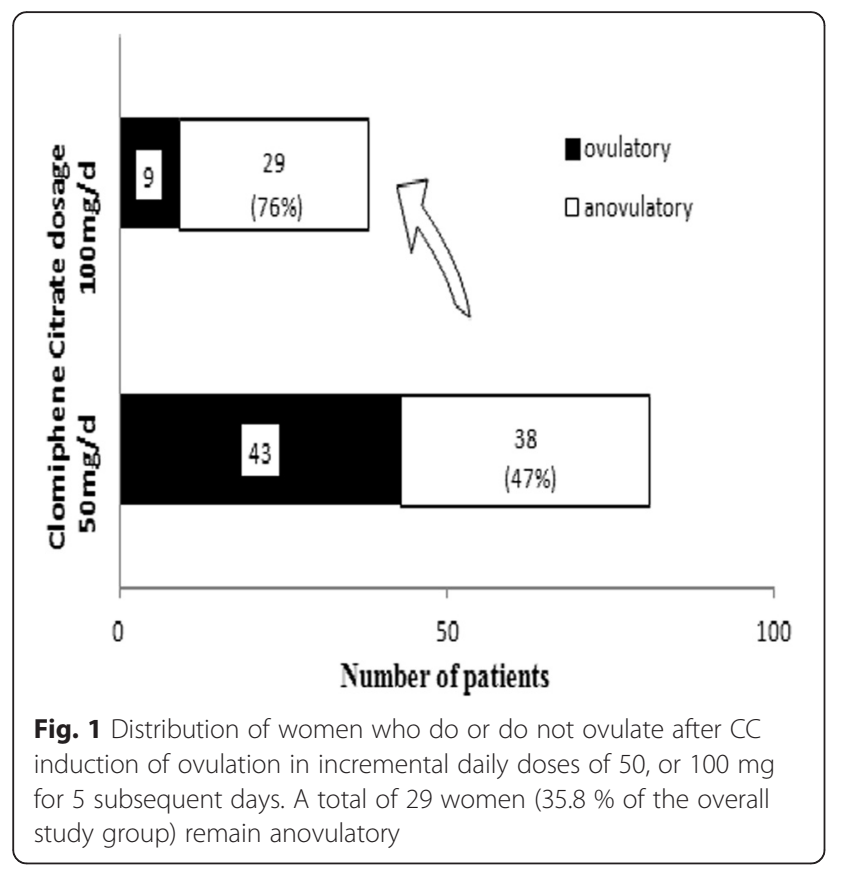

serum AMH and BMI, FSH, LH/FSH, T and HOMA-IR could be found (Table 3). Univariate logistic regression analysis showed that AMH, AFC and ovarian volume were significant predictors of ovarian response to CC stimulation. For the multivariate logistic regression analysis using stepwise forward selection on all variables, AMH was selected in the final model, while mean ovarian volume and AFC were not (date were not shown).

Figure 2 presents ROC for the sensitivity and specificity of the $\mathrm{AMH}$ at different levels in predicting no ovulation after $\mathrm{CC}$ therapy. The $\mathrm{AMH}$ shows a ROCAUC of 0.813 for no ovulation, indicating a useful potential for predicting CRA. Considering a serum AMH concentration of $7.77 \mathrm{ng} / \mathrm{ml}$ as cut-off,

Table 2 Comparison the characteristics of PCOS women who conceived on CC treatment $(n=26)$ and those who did not conceive $(n=55)$

\begin{tabular}{lccl}
\hline & $\begin{array}{l}\text { Pregnant } \\
n=26\end{array}$ & $\begin{array}{l}\text { Nonpregnant } \\
n=55\end{array}$ & $P$ value \\
\hline Age (years) & $27.08 \pm 2.23$ & $26.40 \pm 2.65$ & NS \\
BMI (kg/m2) & $23.46 \pm 2.83$ & $23.94 \pm 2.77$ & NS \\
LH(IU/L) & $8.05 \pm 2.12$ & $8.40 \pm 2.50$ & NS \\
FSH(IU/L) & $5.55 \pm 1.3$ & $5.82 \pm 1.14$ & NS \\
LH/FSH & $1.55 \pm 0.65$ & $1.51 \pm 0.57$ & NS \\
T(ng/ml) & $0.55 \pm 0.22$ & $0.58 \pm 0.27$ & NS \\
HOMA-IR & $3.02 \pm 1.35$ & $3.27 \pm 2.69$ & NS \\
Ovarian volume (ml) & $9.52 \pm 1.28$ & $10.27 \pm 1.48$ & $<0.05$ \\
AFC (n) & $15.04 \pm 2.82$ & $16.62 \pm 3.98$ & NS \\
AMH & $4.81 \pm 2.06$ & $6.89 \pm 2.95$ & $<0.01$ \\
\hline
\end{tabular}

Table 3 Spearman's correlations between plasma AMH and other factors in women with PCOS

\begin{tabular}{lcl}
\hline Variable & $r$ & $P$ value \\
\hline Age (years) & -0.012 & NS \\
BMI (kg/m2) & 0.027 & NS \\
LH (IU/L) & 0.253 & $<0.05$ \\
FSH(IU/L) & -0.06 & NS \\
LH/FSH & 0.207 & NS \\
T(ng/ml) & 0.065 & NS \\
HOMA-IR & 0.016 & NS \\
Ovarian volume (ml) & 0.297 & $<0.01$ \\
AFC $(n)$ & 0.296 & $<0.01$ \\
\hline
\end{tabular}

the sensitivity and specificity of predicting no ovulation were 92 and $65 \%$ respectively. With this cut-off $(7.77 \mathrm{ng} / \mathrm{ml})$, the outcomes of CC ovarian stimulation were compared between cycles with high AMH vs. low AMH levels. Patients with AMH levels less than $7.77 \mathrm{ng} / \mathrm{ml}$ had significantly higher ovulation and pregnancy rates than those with AMH of $7.77 \mathrm{ng} / \mathrm{ml}$ or greater. In addition, patients with high AMH levels had significantly higher LH, ovarian volume and AFC (Table 4).

\section{AMH and dose of CC}

The mean serum concentration of AMH was compared between PCOS patients who responded to CC $50 \mathrm{mg}(n=43)$ vs those who responded to the higher dose $100 \mathrm{mg}(n=9)$. The results showed a significant

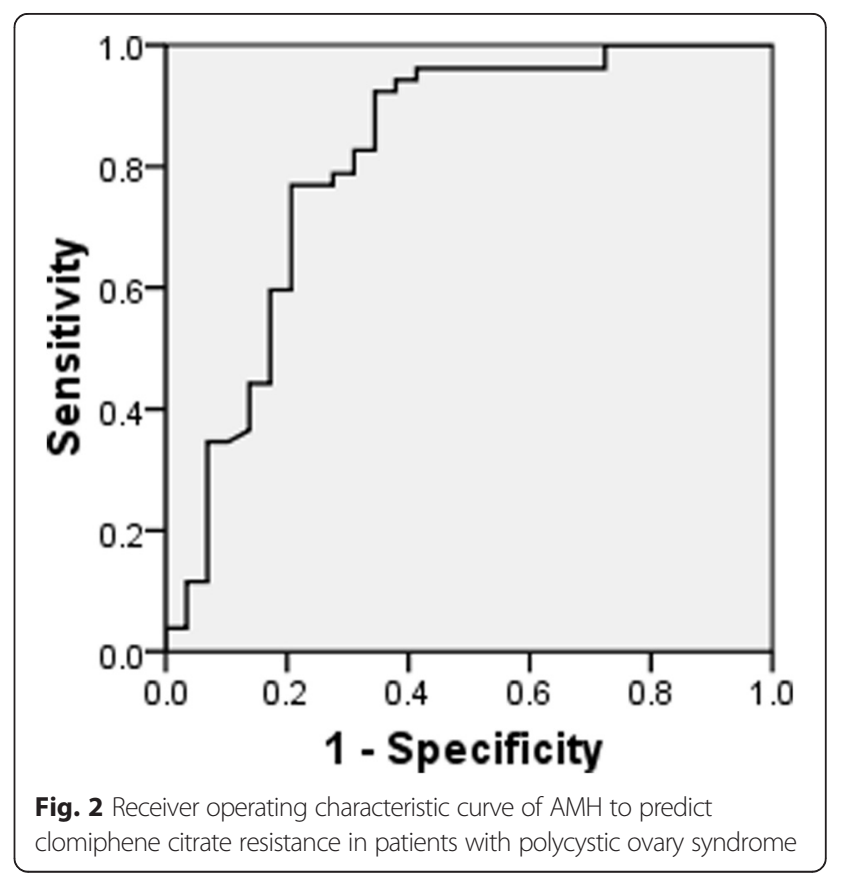


Table 4 Comparison of PCOS women with high vs low AMH using a cutoff value of $7.77 \mathrm{ng} / \mathrm{ml}$

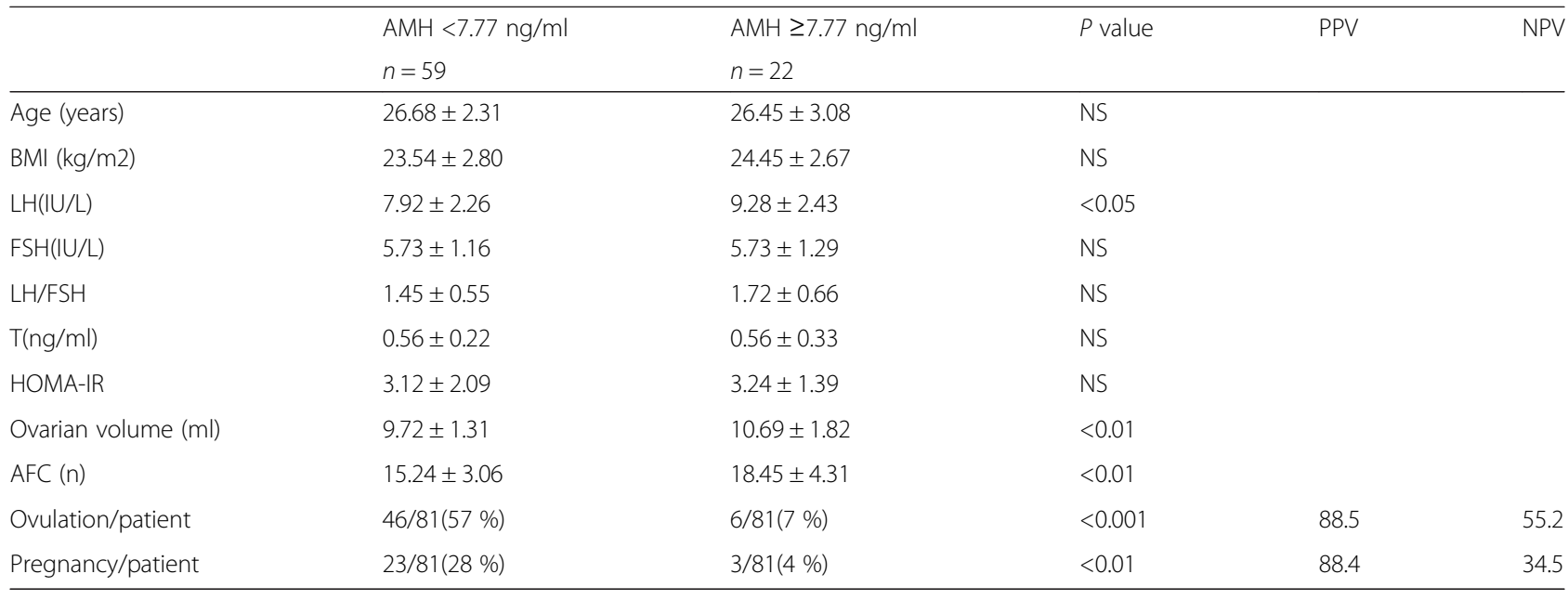

$(P<0.05)$ increase of serum AMH level with the increasing dose of CC (Table 5).

\section{Discussion}

Since the increased AMH would impair the action of FSH and contribute to the FA of PCOS, this evidence has led us to hypothesise that there is a subgroup of women with PCOS who have the higher levels of AMH and who are the more resistant to CC treatment. In this study, we really proved that patients with high $\mathrm{AMH}$ level are less likely to respond to CC treatment. Furthermore, we have identified a cut-off level of $\mathrm{AMH}$ $(7.77 \mathrm{ng} / \mathrm{ml})$, above which the chances of ovulation seem to be significantly reduced. These observations suggest that high AMH values reflect more impaired disruption in folliculogenesis and granulosa cell function.

However, it may seem paradoxical that serum AMH concentrations are known to positively predict ovarian response to gonadotrophin stimulation during IVF. For women with high AMH levels are considered to predict excessive ovarian response to gonadotropin. Meanwhile, low AMH levels indicative of a diminished ovarian reserve, is associated with poor response [17, 18]. Amer SA et al. [13] explained the contradiction may be due to the different spectrum of circulating $\mathrm{AMH}$ in women with and without PCOS. Since AMH levels were significantly increased in women with PCOS, they considered

Table 5 Serum AMH concentrations in PCOS patients achieving ovulation on different doses of CC

\begin{tabular}{|c|c|c|c|c|}
\hline \multirow{2}{*}{$\begin{array}{l}\text { Dose } \\
\text { (mg) }\end{array}$} & \multicolumn{2}{|l|}{ Clinical outcome } & \multirow{2}{*}{$\begin{array}{l}\text { AMH } \\
\text { levels } \\
\text { achieving } \\
\text { ovulation }\end{array}$} & \multirow[t]{2}{*}{$P$ value } \\
\hline & Not ovulated, n (\%) & Ovulated, n (\%) & & \\
\hline 50 & $38(46.9)$ & $43(53.1)$ & $5.07 \pm 1.8$ & - \\
\hline 100 & $29(76.3)$ & $9(23.7)$ & $6.64 \pm 2.34$ & $<0.05^{*}$ \\
\hline
\end{tabular}

Note: *The mean AMH levels was compared between PCOS patients who responded to CC $50 \mathrm{mg}$ vs those who responded to the dose $100 \mathrm{mg}$ levels above the optimum AMH values are associated with poor ovarian response to stimulation. It is interesting to note that, in contrast to Amer SA's opinion, Kaya et al. [19] and our previous study [12] found a positive association between serum AMH levels and ovarian responsiveness to gonadotrophins during IVF in women with PCOS. In that study as serum AMH levels increased, an increase in estrodiol levels on the day of hCG administration and the number of retrieved oocytes were observed, while the total dose of the gonadotrophins was significantly decreased. Thus, we suppose the predictive role of AMH is different in ovarian responsiveness to ovulation induction with $\mathrm{CC}$ and ovarian hyperstimulation with gonadotrophins for IVF treatment, because the goal of stimulation in women with anovulation is different than that in women undergoing IVF.

It is sopposed that in anovulatory women with PCOS, increasing the serum FSH level may reduce the $\mathrm{AMH}$ excess, thus relieving its inhibition on the follicular growth, and allowing the emergence of a dominant follicle [20]. In ovulation induction the aim should be to achieve the ovulation of a single follicle, CC thus constitutes the first line treatment of choice in PCOS women. Chronic low-dose gonadotrophins (with a starting dose 37.5 or $50 \mathrm{U}$ daily) have been used to stimulate ovulation in women who fail to ovulate with CC. However, both $\mathrm{CC}$ and low-dose gonadotrophins make the serum FSH levels increased gently and may be not enough to reduce intra-ovarian $\mathrm{AMH}$ to a level consistent with resumption of ovulation in women with high AMH level. Therefore, as expected the patient with higher AMH were more deeply inhibited and more likely to remain anovulatory after ovulation induction. The aim of IVF treatment, however, is normally designed to promote multifollicular development and as such will usually employ higher doses of FSH (with a starting dose at least 
112.5U daily) than those used for ovulation induction. When the 'threshold' level of FSH for follicular growth is quickly exceeded and follicle arrest from $\mathrm{AMH}$ inhibition was relieved, resulting in an early visualization of multiple dominant follicles development.

Our findings are consistent with previous study by Mahran A and co-workers [21] who have evaluated the impact of circulating $\mathrm{AMH}$ on the success rates of $\mathrm{CC}$ ovulation induction in 60 women with anovulatory PCOS receiving 187 cycles of treatment, and found circulating AMH levels to be negatively correlated with the chances of ovulation. Simially, Amer SA et al. [13] have evaluated the impact of circulating $\mathrm{AMH}$ on the outcome of ovarian stimulation in 20 women with anovulatory PCOS undergoing 34 cycles of gonadotrophin treatment. They found circulating $\mathrm{AMH}$ levels to be negatively correlated with ovarian response to human menopausal gonadotrophin. On the other hand, our findings concur with those of El-Halawaty et al. [22], in that $\mathrm{AMH}$ levels were significantly higher in responders to $\mathrm{CC}$ therapy when compared to non-responder. However, their findings included a subgroup of obese PCOS women receiving a high dose of CC $(150 \mathrm{mg} / \mathrm{d})$. Only $25 \%$ of participants in that study ovulated in response to the high $\mathrm{CC}$ in first cycle, which is much lower than the majority of publications reporting ovulation rates of 75-80\% after CC treatment [8].

$\mathrm{AMH}$ was reported to be one of the local inhibitors of FSH action by decreasing granulosa cell sensitivity to FSH [23, 24], since the antral follicles from AMH knockout mice are more sensitive to FSH than those from the wild type [25]. This effect of AMH was mainly the result of inhibited aromatase activity in granulosa cell. In keeping with this study, an inhibitory effect of $\mathrm{AMH}$ on FSH- induced aromatase mRNA expression and estradiol production has been shown in human GLCs [26]. Similarly, the inverse relationship between AMH and estradiol has also been found in PCOS women [6]. The fact that $\mathrm{AMH}$ is inhibitory to factors required for follicle growth and subsequently selection process of the dominant follicle [3], thus it is not surprising that $\mathrm{AMH}$ is a negatively predictive factor for ovarian response to $\mathrm{CC}$ therapy in PCOS women.

It is of note that AMH, LH, AFC and ovarian volume are closely related. Furthermore, AFC and ovarian volume were significantly higher in the CRA group compared with responder. These may therefore be confounding factors that could have an influence on responsiveness to $\mathrm{CC}$. So we have used multiple logistic regression analysis to determine which of these factors is an independent predictor of ovulation. The analysis has shown that AMH serum level is the best overall predictor of ovarian response to $\mathrm{CC}$ treatment.
In current study, the AMH levels were significantly higher in non-pregnancy compared with pregnancy group. However, this difference was disappeared when CC-resistant women were excluded from the analyses. This may be due to the fact that most CC resistant patients in this study had relatively higher $\mathrm{AMH}$ were excluded from the non-pregnancy group.

In the present study, we found serum $\mathrm{AMH}$ levels with a threshold of $7.77 \mathrm{ng} / \mathrm{ml}$ had a sensitivity of $92 \%$ and specificity of $65 \%$ in predicting ovarian response to CC. This cut-off is greater than two times those of previously reported by Mahran A et al. [21] who reported that $3.4 \mathrm{ng} / \mathrm{ml}$ was an optimal cut-off for the prediction of CRA among 60 women with PCOS. It is possible that different kits for detecting $\mathrm{AMH}$ might result in substantial variation in the serum level of $\mathrm{AMH}$. In addition, variations in PCOS manifestations and $\mathrm{AMH}$ across different racial/ethnic backgrounds may be ascribed to these differences. Therefore, it should be noted that our cutoff AMH level applies only to the AMH kit used in this study. More studies are needed to test which value would be most useful in clinical practice.

The main strength of this study is its prospective design with inclusion of anovulatory patients fulfilling the study inclusion. However, our study has certain limitations that should be noted. Definitions vary the dose required to define CC-resistance ranging from $100 \mathrm{mg}$ to150 $\mathrm{mg}$ of CC $[27,28]$. In the present study, we defined $\mathrm{CC}$-resistance as failure to ovulate in three $\mathrm{CC}$ cycles with the maximum dose $100 \mathrm{mg}$ of CC. The CC non-responder in our study may ovulate in response to $150 \mathrm{mg}$ of CC administration. However, the doses in excess of $100 \mathrm{mg}$ per day are not approved by Food and Drug Administration of United States. Therefore, we did not prescribe more than $100 \mathrm{mg}$ per day of $\mathrm{CC}$ in this study.

\section{Conclusions}

In summary, this study demonstrates that the plasma $\mathrm{AMH}$ can predict ovarian response to $\mathrm{CC}$ treatment. Therefore, measurement of serum AMH concentration for anovulatory women with PCOS before treatment may be a useful tool in predicting the outcome of $\mathrm{CC}$ administration. This could help with counselling PCOS patients concerning the expected success of CC treatment and may render the ovulation-induction protocols more patient-tailored and more cost-effective.

\section{Abbreviations}

AFC: antral follicles count; AMH: Anti-Müllerian hormone; BMl: body mass index; CC: clomiphene citrate; CRA: CC-resistant anovulation; FA: follicular arrest; FSH: Follicle stimulating hormone; hCG: Human chorionic

gonadotrophin; HOMA-IR: homeostasis model assessment insulin resistance index; IVF: In-vitro fertilisation; LH: Luteinizing hormone; PCOS: Polycystic ovarian syndrome; ROC: Receiver operating characteristic; T: testosterone. 


\section{Competing interests}

The authors declare that they have no competing interests.

\section{Authors' contributions}

HM designed the study, carried out statistical analysis and drafted the manuscript. YY and XZ conceived of the study, obtained ethics approval and helped to draft the manuscript. SF recruited patients and collected blood samples. WX carried out AMH assays and collected data for analysis, reviewed the design and critically reviewed the manuscript. ML participated in the design of the study and critically reviewed the manuscript. All authors read and approved the final manuscript.

\section{Acknowledgements}

This study was funded by The Second Affiliation Hospital of Xi an JiaoTong University. We would like to express our gratitude to Shankun Liu for his help in statistical analysis and thank Xiaoning Lu for her invaluable help in the collection and storage of data.

\section{Author details}

${ }^{1}$ Department of Obstetrics and Gynaecology, The Second Affiliated Hospital of Xi'an Jiaotong University, No. 157, Xiwu Road, Xi'an City 710004 Shaanxi Prov., China. ${ }^{2}$ Department of Obstetrics and Gynaecology, The Second Affiliated Hospital of Shaanxi University of Chinese Medicine, Xianyang City 712000 Shaanxi Prov., China.

\section{Received: 26 November 2015 Accepted: 3 February 2016}

\section{Published online: 11 February 2016}

\section{References}

1. Norman RJ, Dewailly D, Legro RS, Hickey TE. Polycystic ovary syndrome. Lancet. 2007:370:685-97.

2. Webber LJ, Stubbs S, Stark J, Trew GH, Margara R, Hardy K, et al. Formation and early development of follicles in the polycystic ovary. Lancet. 2003;27:1017-21.

3. Jonard S, Dewailly D. The follicular excess in polycystic ovaries due to intraovarian hyperandrogenism, may be the main culprit for the follicular arrest. Hum Reprzod Update. 2004;10:107-17.

4. Pigny $P$, Merlen E, Robert $Y$, Cortet-Rudelli $C$, Decanter $C$, Jonard $S$, et al. Elevated serum level of anti-Mullerian hormone in patients with polycystic ovary syndrome: relationship to the ovarian follicle excess and to the follicular arrest. J Clin Endocrinol Metab. 2003;88:5957-62.

5. Pigny $P$, Jonard $S$, Robert $Y$, Dewailly $D$. Serum anti-Mullerian hormone as a surrogate for antral follicle count for definition of the polycystic ovary syndrome. J Clin Endocrinol Metab. 2006;91:941-5.

6. Cook $C L$, Siow Y, Brenner AG, Fallat ME. Relationship between serum Mullerian-inhibiting substance and other reproductive hormones in untreated women with polycystic ovary syndrome and normal women. Fertil Steril. 2002;77:141-6.

7. Laven JS, Mulders AG, Visser JA, Themmen AP, Jong FH, Fauser BC. AntiMullerian hormone serum concentrations in normovulatory and anovulatory women of reproductive age. J Clin Endocrinol Metab. 2004:89:318-23.

8. Mitwally MF, Casper RF. Use of an aromatase inhibitor for induction of ovulation in patients with an inadequate response to clomiphene citrate. Fertil Steril. 2001;75:305-9.

9. Broer SL, Mol BW, Hendriks D, Broekmans FJ. The role of anti-Mullerian hormone in prediction of outcome after IVF: comparison with the antral follicle count. Fertil Steril. 2009;91:705-14.

10. Elgindy EA, El-Haieg DO, El-Sebaey A. Anti-Mullerian hormone: correlation of early follicular, ovulatory and midluteal levels with ovarian response and cycle outcome in intracytoplasmic sperm injection patients. Fertil Steril. 2008;89:1670-6.

11. Lekamge DN, Barry M, Kolo M, Lane M, Gilchrist RB, Tremellen KP. AntiMullerian hormone as a predictor of IVF outcome. Reprod Biomed Online. 2007; 14:602-10

12. Xi W, Gong F, Lu G. Correlation of serum Anti-Mullerian hormone concentrations on day 3 of the in vitro fertilization stimulation cycle with assisted reproduction outcome in polycystic ovary syndrome patients. J Assist Reprod Genet. 2012;29:397-402.

13. Amer SA, Mahran A, Abdelmaged A, El-Adawy AR, Eissa MK, Shaw RW. The influence of circulating anti-Müllerian hormone on ovarian responsiveness to ovulation induction with gonadotrophins in women with polycystic ovarian syndrome: a pilot study. Reprod Biol Endocrinol. 2013;11:115.
14. Rotterdam ESHRE/ASRM-Sponsored PCOS Consensus Workshop Group. Revised 2003 consensus on diagnostic criteria and long-term healthy risks related to polycystic ovary syndrome. Fertil Steril. 2004;81:19-25.

15. Matthews DR, Hosker JP, Rudenski AS, Naylor BA, Treacher DF, Turner RC. Homeostasis model assessment: insulin resistance and beta-cell function from fasting plasma glucose and insulin concentrations in man. Diabetologia. 1985;28:412-9.

16. Balen AH, Laven JS, Tan SL, Dewailly D. Ultrasound assessment of the polycystic ovary: international consensus definitions. Hum Reprod Update. 2003;9:505-14

17. La Marca A, Sighinolfi G, Radi D, Argento C, Baraldi E, Artenisio AC, et al. Anti-Mu llerian hormone (AMH) as a predictive marker in assisted reproductive technology (ART). Hum Reprod Update. 2010;16:113-30.

18. Nakhuda GS, Chu MC, Wang JG, Sauer MV, Lobo RA. Elevated serum müllerian-inhibiting substance may be a marker for ovarian hyperstimulation syndrome in normal women undergoing in vitro fertilization. Fertil Steril. 2006:85:1541-3.

19. Kaya C, Pabuccu R, Satlroglu H. Serum antimullerian hormone concentrations on day 3 of the in vitro fertilization stimulation cycle are predictive of the fertilization, implantation, and pregnancy in polycystic ovary syndrome patients undergoing assisted reproduction. Fertil Steril. 2010;94:2202-7.

20. Catteau-Jonard S, Pigny P, Reyss AC, Decanter C, Poncelet E, Dewailly D. Changes in serum anti-Mu"llerian hormone level during low-dose recombinant follicular-stimulating hormone therapy for anovulation in polycystic ovary syndrome. J Clin Endocrinol Metab. 2007:92:4138-43.

21. Mahran A, Abdelmeged A, El-Adawy AR, Eissa MK, Shaw RW, Amer SA. The predictive value of circulating anti-müllerian hormone in women with polycystic ovarian syndrome receiving clomiphene citrate: A prospective observational study. J Clin Endocrinol Metab. 2013;98:4170-5.

22. El-Halawaty S, Rizk A, Kamal M, Aboulhassan M, Al-Sawah H, Noah O, et al. Clinical significance of serum concentration of anti-Müllerian hormone in obese women with polycystic ovary syndrome. Reprod Biomed Online. 2007;15:495-9.

23. Durlinger AL, Gruijters MJ, Kramer P, Karels B, Kumar TR, Matzuk MM, et al. Anti-Mullerian hormone attenuates the effects of FSH on follicle development in the mouse ovary. Endocrinology. 2001:142:4891-9.

24. Durlinger AL, Visser JA, Themmen AP. Regulation of ovarian function: the role of Anti-Mullerian hormone. Reproduction. 2002;124:601-9.

25. Durlinger AL, Kramer P, Karels B, de Jong FH, Uilenbroek JT, Grootegoed JA, et al. Control of primordial follicle recruitment by anti-Mullerian hormone in the mouse ovary. Endocrinology. 1999;140:5789-96.

26. Grossman MP, Nakajima ST, Fallat ME, Siow Y. Mullerian-inhibiting substance inhibits cytochrome P450 aromatase activity in human granulosa lutein cell culture. Fertil Steril. 2008;89:1364-70.

27. Verit FF, Erel O, Kocyigit A. Association of increased total antioxidant capacity and anovulation in nonobese infertile patients with clomiphene citrate-resistant polycystic ovary syndrome. Fertil Steril. 2007:88:418-24.

28. Ahmed MI, Duleba AJ, El Shahat O, Ibrahim ME, Salem A. Naltrexone treatment in clomiphene resistant women with polycystic ovary syndrome. Hum Reprod. 2008;23:2564-9.

\section{Submit your next manuscript to BioMed Central and we will help you at every step:}

- We accept pre-submission inquiries

- Our selector tool helps you to find the most relevant journal

- We provide round the clock customer support

- Convenient online submission

- Thorough peer review

- Inclusion in PubMed and all major indexing services

- Maximum visibility for your research

Submit your manuscript at www.biomedcentral.com/submit
Biomed Central 